\title{
Law and Economics of Environmental Insurance (Editorial)
}

\author{
Donatella Porrini \\ Facoltà di Economia Ecotekne, Università di Lecce, Via per Monteroni, Lecce 73100, Italy. \\ E-mail: d.porrini@economia.unile.it
}

The Geneva Papers (2008) 33, 269-273. doi:10.1057/gpp.2008.11

Keywords: environmental insurance; law and economics; insurability

The topic of environmental insurance is complex in several ways and requires a particular attention. A law and economics perspective could help to solve multiple problems that arise in connection with these kinds of insurance policies and especially the ones covering industrial and technological risks.

The first problem is the role of insurance in providing a mechanism through which the potential injurers internalize the risk costs they generate by their activity. ${ }^{1}$ Another problem is how to guarantee a sufficient compensation for the victims in case of an accident at a sustainable cost, and which legal regime may provide necessary incentives for prevention. ${ }^{2}$ Moreover, environmental risks pertain to the category of potentially catastrophic risks presenting peculiarities that differentiate them from traditional risks: they might have relevant and long-term consequences for the environment and human health. ${ }^{3}$

For the insurability, a difficult task is to determine with a sufficient degree of accuracy the probability of occurrence and the magnitude of environmental damages. But the insurability of environmental risks, and especially major accidents, is also very much influenced by changes in the regulatory system.

At the European Community level, the Directive 2004/35/CE established a general discipline for the prevention and the remedy of ecological damage at reasonable costs. To guarantee the actual effectiveness of this regime and the consequent insurability, it is important to set specific and equal criteria in all the European Union countries. Problems arise, for example, in connection with the extension of the guarantee to the first-party clean up and to the natural resources recovery regarding protected species and natural habitats. ${ }^{4}$

\footnotetext{
${ }^{1}$ See Faure and Skogh (2003).

${ }^{2}$ See Porrini (2005).

${ }^{3}$ See Froot (1999).

${ }^{4}$ Particularly in Italy, the main topic is the reaction by the Italian insurance market to the transposition of the Environmental Liability Directive in the Italian Law (D Lgs n. 152/2006).
} 
Beside their critical position in establishing a system of compulsory environmental coverage, the insurance companies ask for a regulatory framework that increases the insurability of environmental risks, particularly defining an identifiable polluter, a concrete and quantifiable damage, a definite causation, and a clear liability assignment regime. ${ }^{5}$

This set of problems and the consequent debate have motivated The Geneva Association to devote its 12th joint Seminar with the European Association of Law and Economics (EALE) to exploring the issue of "Law and Economics of Environmental Insurance", with special attention to the role of insurance in covering environmental risks, the methods of risk management, and the relationship between insurance and catastrophic risks.

The Seminar was held on 15th and 16th of June 2007 in Lecce, and was supported by The Geneva Association, the Italian Institute for Research and Development of Insurance and the Italian National Insurers Association.

This special issue on the law and economics of environmental insurance contains four papers selected from contributions presented at the seminar. Devoted to the topic of nuclear risks, the first two clarify the problems connected with the insurability of these particular kinds of risks.

Göran Skogh from Linkoping University in Sweden presented at the Seminar the paper "A European Nuclear Accident Pool". The starting point of the author is that despite the fact that the Polluter Pay Principle prevails at nuclear accidents and the plant owner is strictly liable for damage to third parties, problems arise because the potential damage is very large compared to the assets of the liable plant owner and thus the liable party may be unable to compensate the victims. ${ }^{6}$

The present system for compensation based on the Paris (OECD) and Vienna (UN) conventions is insufficient to compensate the victims. The solution for maintaining an efficient incentive to prevent accidents and the compensation to victims has to be provided by the European Union and the liability should be strictly on the Member State that permits nuclear power production on its territory.

The paper suggests that a large claim could be covered by mutual risk-sharing by the pool of Member States on the basis of the "Restated Diversification Theorem", 7 which says that sharing is mutually beneficial to risk averse parties. The pool can obtain a collective incentive to control the accident risk. The accident risk, as well as the burden of the pool of Member States, can be reduced by liability redressed to the nuclear industry. The Member States could also influence the nuclear production by the restrictions in permits, zoning and safety regulation.

The second paper by Michael Faure from Mastricht University and Karine Fiore from Paul-Cézanne University in Aix-en-Provence is about "The Coverage of the Nuclear Risk in Europe: Which Alternative?".

The starting point is a critical view of the actual compensation regime for nuclear accidents as defined by international conventions for different reasons: the low

\footnotetext{
${ }^{5}$ See Van den Bergh and Faure (2006).

${ }^{6}$ This is the judgement proof problem. See Shavell (1986).

${ }^{7}$ Skogh and Wu (2005).
} 
financial cap may provide insufficient deterrence for prevention to the nuclear operator; the financial cap (combined with the public compensation scheme) constitutes a subsidy to the nuclear power since full costs are not internalized $;^{8}$ and, notwithstanding the public compensation scheme, victims can never be fully compensated in case of a major nuclear accident.

As with the first paper by Skogh about a pooling by nuclear operators, Faure and Fiore examine generally whether the risk sharing by nuclear operators could constitute a serious alternative for the current coverage system. In order to examine this alternative, the concrete context of nuclear operators in Europe is examined together with the financial consequences for nuclear operators of such a risk-sharing agreement.

But here the main point is the quantitative analysis of the three possibilities to finance a risk-sharing agreement: first, an operator pays contributions ex ante; second, an operator makes reservations ex ante; third, as in the U.S. today, the payment is made by retrospective contributions, after the accident happened. Through calculations, the retrospective contributions appear to be a cheap way of constituting the contributions to the risk sharing, assuming that the cost of guarantee is zero or low. Moreover, risk sharing (no matter how it is financed) is always substantially cheaper than the current model of compensation through insurance and reserves.

These two papers appear to be relevant contributions to the development of a compensation model for nuclear accidents that leads to an internalization of the nuclear risk. Erik Lenntorp from Linkoping University investigates the Swedish institutions for flood risk management that currently consist of a combination of regulation, liability rules, land-use regulations, and insurance, starting from the distinction between two different sources of flood risks by a hydroelectric dam.

On the one hand, a dam may break causing a potential catastrophe with large losses to property and eventually to lives. The causes of a dam break are largely within the control of the dam owner (the design of the dam, the amount of water stored in the reservoir and safety efforts). On the other hand, floods may also occur when a dam does not break for a natural event (large amounts of precipitation causing "high flows"). In this case, the dam owner can significantly contribute to the risk of a flood by the amount of water stored in the reservoir.

The paper's main topic is the comparison in terms of social welfare between strict liability and negligence in the assignment of liability to the dam owner. The focus is on the interdependency of the risk of dam break and measures to avoid high flow floods. Given that a dam break is likely to have catastrophic consequences, the safety is the first priority for the authorities and the question is of what are the appropriate institutions to control this risk, the institutional frame for the liability regime.

In contrast to previous contributions, ${ }^{9}$ the conclusions support the maintaining of the current negligence regime mainly because damages from high flow floods are best

\footnotetext{
${ }^{8}$ About the inefficiency of the financial caps: see Faure and Van den Bergh (1990), Trebilcock and Winter (1997).

${ }^{9}$ Mantaye (2002) argued that the liability rule should be changed from negligence to strict liability, the main argument being that strict liability would cause hydropower producers to internalize flood damages when they decide on how much water to store in the reservoirs.
} 
managed by increasing the incentives for downstream property owners to take flood risk into account when developing their properties. This should be done by a better awareness of flood risk in physical planning, when granting building licenses to downstream property owners, and by a better pricing of this risk in the property insurance.

The paper "The Efficient Liability Sharing Factor for Environmental Disasters: Lessons for Optimal Insurance Regulation", by Marcel Boyer (Université de Montréal) and Donatella Porrini (Università del Salento), deals with the interactions of actors and stakeholders engaged in activities associated with environmental risks, namely governments, firms and financiers that cover part of the risk, and judicial courts.

Traditional liability insurance and financial responsibility are analyzed in their practical application as instruments to involve the insurance company in the internalization of environmental damage, compensation of the victims, and clean up of the sites. In this sense, by imposing a liability-sharing factor, the government delegates to the insurers part of the control of the firm's prevention measures. Moreover, the courts play a role monitoring the prevention measures adopted when a suing strategy is followed by the insurance company to recover part of the shared damage in case of a favourable judicial decision.

A structural model is presented characterizing the distortions in environmental liability sharing between firms and insurers that the imperfect implementation of government policies implies, and considering also the role of the courts. ${ }^{10}$ Comparative statics results are derived indicating how sensitive the liability-sharing factor is to changes in parameters (parameters that underlie the firm profit level and volatility, the cost of safety care, the monitoring cost, the social cost of public funds, and the effectiveness of care in reducing the probability of accident) that are relevant for the characterization of optimal policies (liability sharing, safety care standards) toward environmental protection or the prevention of industrial accidents.

With these papers, the journal addresses many topics related to "Law and Economics of Environmental Insurance" following both a legal and an economic approach. Moreover, the Seminar was characterized by the contribution of speakers from institutions operating in the field, from authorities and from leading insurance companies. The articles incorporate the very interesting and fruitful discussion that followed the presentations. The authors of the papers benefit from messages coming from the general discussion to devote increasing attention to the issue of the development of environmental insurance for its fundamental role in implementing an efficient environmental policy at European Union level.

\section{References}

Boyer, M. and Porrini, D. (2004) 'Modeling the choice between regulation and liability in terms of social welfare', Canadian Journal of Economics/Revue canadienne d'Economie 37: 590-612.

${ }^{10}$ Differently from other papers of the two authors: Boyer and Porrini $(2004,2006)$. 
Boyer, M. and Porrini, D. (2006) 'Sharing liability between banks and firms: The case of industrial safety risk' (chapter 13), in M. Boyer, Y. Hiriart and D. Martimort (eds) Frontiers in the Economics of Environmental Regulation and Liability, Aldershot, UK: Ashgate Publishing, pp. 311-341.

Faure, M. and Skogh, G. (2003) The Economic Analysis of Environmental Policy and Law, Cheltenham, UK: Edward Elgar.

Faure, M. and Van den Bergh, R. (1990) 'Liability for nuclear accidents in Belgium from an interest group perspective', International Review of Law \& Economics 10: 241-254.

Froot, K.A. (1999) 'The evolving market for catastrophe risk', Risk Management and Insurance Review 2: $1-28$.

Mantaye, A. (2002) 'An economic analysis of a Swedish hydropower plant liability case', The Geneva Papers on Risk and Insurance - Issues and Practice 27: 626-637.

Porrini, D. (2005) 'Environmental policies choice as an issue of informational efficiency', in J.G. Backhaus (ed) The Elgar Companion to Law and Economics, Cheltenham, UK: Edward Elgar, pp. 350-363.

Shavell, S. (1986) 'The judgement proof problem', International Review of Law and Economics 1: 43-58.

Skogh, G. and Wu, H. (2005) 'The diversification theorem restated: Risk-pooling without assignment of probabilities', Journal of Risk and Uncertainty 31: 35-51.

Trebilcock, M. and Winter, R.A. (1997) 'The economics of nuclear accident law', International Review of Law \& Economics 17: 215-243.

Van den Bergh, R. and Faure, M. (2006) 'Compulsory insurance of loss to property caused by natural disasters: Competition or solidarity?', World Competition 29: 25-54.

\section{About the author}

Donatella Porrini is Associate Professor in Economics, University of Lecce since 2004. She is the author of research in Law and Economics, particularly related to insurance and bank markets regulatory issues. She is the author also of articles about the economic analysis of responsibility for environmental damage. 